\title{
Análise de custos e rendimentos de sistemas agroflorestais na Zona da Mata (MG)
}

Sidney Araujo Cordeiro ${ }^{1}$

Marcio Lopes da Silva²

Silvio Nolasco de Oliveira Neto ${ }^{3}$

Tiago Moreira de Oliveira ${ }^{4}$

Kaio César Mendes da Silva Nery ${ }^{5}$

\section{Resumo}

Esta pesquisa teve como objetivo levantar os custos de produção de sistemas agroflorestais implantados na Zona da Mata (MG), e realizar simulação visando melhorias nesses sistemas. Utilizou-se os dados de projetos referentes às Unidades de Experimentação Integração Lavoura Pecuária e Floresta, nos anos de 2007/2008, fornecidos pela Empresa de Assistência Técnica e Extensão Rural de Minas Gerais e pela Universidade Federal de Viçosa. Os custos de produção do sistema agroflorestal em questão foram comparados com o monocultivo do eucalipto, bem como variação das receitas devido à variação no espaçamento de plantio. Verificou-se que o eucalipto em monocultivo apresentou melhores resultados, sendo o projeto mais rentável. Na medida em que se aumenta o espaçamento de plantio das árvores de eucalipto, tem-se um aumento da área disponível para plantio de milho e criação de gado. Mas, como comprovado pelos resultados, esse ganho em área não obtém o mesmo retorno financeiro caso essa área estivesse com plantio de árvores.

Palavras-chave: Agrossilvicultura. Planejamento florestal. Economia florestal.

\section{Introdução}

Em suas condições originais, a formação vegetal que sugeriu o nome da região da Zona da Mata de Minas Gerais formava um todo contínuo com a floresta do médio Paraíba, ao sul, e a do Vale do Rio Doce, ao norte; a oeste limitavam-na os campos naturais do centro e sul de Minas. A cobertura florestal original manteve-se pouco alterada até o início do século XIX. A partir dessa época ocorreu a efetiva ocupação humana da região, por meio de um processo predatório, com o corte raso da floresta, visando destinar áreas para a cafeicultura, pecuária ou simplesmente a comercialização da madeira. Apenas as áreas de difícil acesso permaneceram com menor nível de intervenção antrópica (LOPES et al., 2002).

Para atender à progressiva demanda de produtos agropecuários e florestais, ou seja, da agricultura, silvicultura e pecuária, com as características exigidas pelo mercado, o uso da terra foi intensificado. Por causa disto, novas fronteiras foram abertas em detrimento de uma degradação dos recursos naturais, promovendo uma drástica redução da biodiversidade, em substituição a plantios homogêneos. As monoculturas sucessivas provocaram uma queda da fertilidade natural dos solos e, consequentemente, uma produtividade incompatível com o esperado.

\footnotetext{
${ }^{1}$ Universidade Federal dos Vales do Jequitinhonha e Mucuri, Professor do curso de Engenharia Florestal. Diamantina-MG, Brasil. E-mail: sidney.cordeiro@ufvjm.edu.br. Telefone: (38) 3532-8644. Departamento de Engenharia Florestal-UFVJM, CEP: 39100-000.

2Universidade Federal de Viçosa, Professor do curso de Engenharia Florestal. Viçosa-MG, Brasil. E-mail:marlosil@ufv.br. Telefone: (31) 3892-2466. Departamento de Engenharia Florestal-UFV, CEP: 37560-000.

3Universidade Federal de Viçosa, Professor do curso de Engenharia Florestal. Viçosa-MG, Brasil. E-mail:snolasco@ufv.br. Telefone: (31) 3892-2466. Departamento de Engenharia Florestal-UFV, CEP: 37560-000.

${ }^{4}$ Universidade Federal do Piauí, Graduação em Engenharia Florestal. Bom Jesus-PI, Brasil. E-mail:tiago2703@hotmail.com. Telefone: (89) 3532-2552. Departamento de Engenharia Florestal-UFPI, CEP: 64900-000.

${ }^{5}$ Universidade Federal dos Vales do Jequitinhonha e Mucuri, Mestrando em Ciência Florestal. Diamantina-MG, Brasil. E-mail: kaiocesarnery@gmail.com. Telefone: (38) 3532-8644. Departamento de Engenharia Florestal-UFVJM, CEP: 39100-000.
} 
Sendo assim, uma alternativa para desenvolvimento da Zona da Mata mineira é a utilização de sistemas agroflorestais. Esse sistema vem despertando interesse na amortização de custos, em razão, principalmente, dos altos custos envolvidos na implantação e manutenção de florestas, e devido à necessidade de implementação de projetos que busquem conciliar desenvolvimento econômico e redução de impactos ao meio ambiente.

A maior parte das terras da região está ocupada por pastagens naturais e plantadas (principalmente braquiárias), que suportam rebanhos bovinos predominantes com dupla finalidade (leite e corte), distribuídos em propriedades de portes médio e pequeno. Entre as culturas tradicionais da região, o café foi o mais importante na formação de rendas. A crescente diminuição dos cafezais contribuiu para o esvaziamento da economia regional, ao passo que a liberação da mão-de-obra dessa atividade, não absorvida pelos outros setores, reduziu as oportunidades de trabalho, criando tensões sociais. Atualmente, o café ainda é tradicional na região, havendo também cultivo do milho, gado de leite/corte e a área com o cultivo do eucalipto vem crescendo e se mostrando como uma excelente oportunidade de renda aos produtores rurais.

A produção agrícola atual na Zona da Mata tem três principais características; longo tempo de uso da terra, sistemas de produção em pequena escala e uso de práticas agrícolas tradicionais (VALE, 2004).

Espécies do gênero Eucalyptus vêm sendo muito utilizadas, inclusive em consórcios com outras espécies arbóreas e agrícolas em sistemas agroflorestais, visando principalmente a produção de madeira, devido ao seu rápido crescimento e da qualidade dos produtos finais.

Diante do exposto, o objetivo deste trabalho é realizar um levantamento dos custos de sistemas agroflorestais, verificando a importância da participação do componente agrícola nos sistemas com ou sem eucalipto, na Zona da Mata mineira, bem como simular situações visando melhoria da rentabilidade destes sistemas.

\section{Material e Métodos}

\subsection{Fonte de dados}

Utilizou-se os dados de projetos referentes às Unidades de Experimentação com Integração Lavoura Pecuária e Floresta, conduzidos nos anos de 2007/2008, fornecidos pela Empresa de Assistência Técnica e Extensão Rural de Minas Gerais (EMATER) e pela Universidade Federal de Viçosa (UFV). Esses dados foram coletados junto a proprietários rurais dos municípios de Viçosa, Ponte Nova, São Pedro dos Ferros e Senador Firmino.

Os dados de custos e receitas até o primeiro ano dos sistemas foram coletados de sistemas agroflorestais implantados pela EMATER, e os custos e receitas dos anos seguintes são estimados.

\subsubsection{Descrição das unidades de experimentação}

\section{Unidade Regional: Viçosa, município Viçosa}

Os cultivares utilizados foram Milho DK 747 e gramínea Brachiaria brizanta. Utilizou-se a calagem, na quantidade de 2 toneladas por hectare.

A dessecação (aplicação de herbicida) foi necessária, sendo utilizado o Roundup, na quantidade de cinco litros por hectare.

O espaçamento de plantio do milho foi de $65 \mathrm{~cm}$, totalizando 30.000 plantas/ha. Já a braquiária foi plantada no espaçamento de $65 \mathrm{~cm}$, sendo utilizados $10 \mathrm{~kg}$ de sementes/hectare.

Realizou-se a adubação N-P-K de plantio, 08-28-16, sendo utilizados 500 kg/ha e adubação N-P-K de cobertura, 30-00-10, na quantidade de $300 \mathrm{~kg} / \mathrm{ha}$.

A unidade demonstrativa foi implantada seguindo a tecnologia preconizada para tal. Houve falha no plantio, além de dois longos períodos de estiagem, na emergência e no estágio de 2 pares de folhas, o que comprometeu bastante o desenvolvimento do milho, de maneira que a braquiária 
encontrou melhores condições, competindo com o milho, e reduzindo a produtividade do mesmo.

\section{Unidade Regional: Ponte Nova, município São Pedro dos Ferros}

Os cultivares utilizados foram Milho BM 2202 e gramínea Brachiaria brizanta.

Utilizou-se a calagem, na quantidade de 0,6 toneladas por hectare.

A aplicação de herbicida foi necessária, sendo utilizado o Roundup, na quantidade de dez litros por hectare e DMA na quantidade de três litros por hectare.

O espaçamento de plantio do milho foi de $100 \mathrm{~cm}$, totalizando 45.000 plantas/ha. Já a braquiária foi plantada no espaçamento de $50 \mathrm{~cm}$, sendo utilizados $20 \mathrm{~kg}$ de semen-tes/hectare.

Realizou-se a adubação N-P-K de plantio, 08-28-16, sendo utilizados $400 \mathrm{~kg} / \mathrm{ha}$ e adubação N-P-K de cobertura 30-00-10, na quantidade de $400 \mathrm{~kg} / \mathrm{ha}$.

\section{Unidade Regional: Viçosa, município Senador Firmino}

Os cultivares utilizados foram milho Biomatrix BRS 2110, gramínea Brachiaria brizanta, Brachiaria decumbens e Eucalyptus urophyla.

Utilizou-se a calagem (agrosilício), na quantidade de 2,5 toneladas por hectare.

A aplicação de herbicida foi necessária, sendo utilizado o Roundup, na quantidade de 3,5 l/ha.

O espaçamento de plantio do milho foi de $90 \mathrm{~cm}$, totalizando 50.000 plantas/ha. Já a braquiária foi plantada no espaçamento de $45 \mathrm{~cm}$, sendo utilizados $25 \mathrm{~kg}$ de sementes/hectare. Realizou-se o plantio manual de 75 plantas de eucalipto por hectare.

A adubação N-P-K de plantio para o milho foi a fórmula 08-28-16 + Zn + Bo, sendo utilizados $400 \mathrm{~kg} / \mathrm{ha}$, a adubação da braquiária foi com o superfosfato simples granulado, na quantidade de $100 \mathrm{~kg} / \mathrm{ha}$, e para o eucalipto foi 06-30-06, na quantidade de $50 \mathrm{~kg} / \mathrm{ha}$.

A adubação de cobertura utilizada foi o amônio farelado, na quantidade de 300 kg/ha. No milho foi utilizada calda viçosa, na quantidade de $6,5 \mathrm{~kg} / \mathrm{ha}$ (adubação foliar).

No combate a formigas utilizou-se isca formicida na quantidade de $1,5 \mathrm{~kg} / \mathrm{ha}$.

\subsection{Cenários de simulação}

Realizou-se uma simulação com base na unidade experimental da regional Viçosa, município de Senador Firmino. Variou-se o espaçamento de plantio do eucalipto, bem como todos os custos e receitas do sistema agroflorestal em questão. Os custos de produção do sistema agroflorestal foram comparados com o monocultivo do eucalipto.

O espaçamento de plantio do eucalipto considerado no monocultivo foi de $3 \times 3 \mathrm{~m}$, sendo considerada nos cálculos a área de um hectare. Considerou-se dois cortes da floresta, sendo o primeiro aos sete anos, visando à produção de carvão e o segundo aos 14 anos visando à produção de madeira para serraria.

Considerou-se um Incremento Médio Anual (IMA) de 35 m³/ha/ano, sendo que $40 \%$ da produção de madeira foi destinada à produção de carvão vegetal com índice de conversão volumétrica de 2:1 ( $\mathrm{m}^{3}$ para $\mathrm{mdc}$ ) e 60\% destinada à produção de madeira serrada. 
Na Tabela 1 encontram-se os custos deste projeto.

Tabela 1 - Custos do projeto florestal visando à produção de carvão e madeira para serraria em Senador Firmino (MG).

\begin{tabular}{|c|c|c|c|c|c|c|c|c|}
\hline \multirow{3}{*}{ ITENS DE CUSTO } & \multirow{3}{*}{ Unidade } & \multirow{3}{*}{$\begin{array}{l}\text { Valor } \\
\text { Unitário }\end{array}$} & \multicolumn{6}{|c|}{ Período } \\
\hline & & & \multicolumn{2}{|c|}{ 1..$^{\circ}$ Ano } & \multicolumn{2}{|c|}{ 2. ${ }^{\circ}$ Ano } & \multicolumn{2}{|c|}{$3 .^{\circ}$ ano } \\
\hline & & & Quant & Valor & Quant & Valor & Quant & Valor \\
\hline \multicolumn{9}{|l|}{ 1. INSUMOS } \\
\hline Mudas (Plantio e Replantio) & ud & 0,30 & 1280 & 384,00 & & & & \\
\hline Irrigação & ud & 110,00 & 2 & 220,00 & & & & \\
\hline Calcário & $\mathrm{t}$ & 85,00 & 0,11 & 9,35 & & & & \\
\hline \multicolumn{9}{|l|}{ Fertilizantes } \\
\hline Nitrogênio - N & $\mathrm{Kg}$ & 2,95 & 20 & 59,00 & & & & \\
\hline Fósforo $-\mathrm{P}_{2} \mathrm{O}_{5}$ & $\mathrm{Kg}$ & 2,67 & 30 & 80,10 & & & & \\
\hline Potássio $-\mathrm{K}_{2} \mathrm{O}$ & $\mathrm{Kg}$ & 3,50 & 20 & 70,00 & & & & \\
\hline Formicida & $\mathrm{Kg}$ & 10,60 & 5 & 53,00 & 4 & 42,40 & 4 & 42,40 \\
\hline Cupinicida & $\mathrm{Kg}$ & 102,00 & 0,2 & 20,40 & 1 & 102,00 & & \\
\hline SUBTOTAL INSUMOS & $\mathbf{R} \mathbf{S}$ & & & 895,85 & & 144,40 & & 42,40 \\
\hline \multirow{3}{*}{ ITENS DE CUSTO } & \multirow{3}{*}{ Unidade } & \multirow{3}{*}{\begin{tabular}{|c|} 
Valor \\
Unitário
\end{tabular}} & \multicolumn{6}{|c|}{ Período } \\
\hline & & & \multicolumn{2}{|c|}{ 1. ${ }^{\circ}$ Ano } & $2 .^{\circ}$ & Ano & \multicolumn{2}{|c|}{$3 .^{\circ}$ ano } \\
\hline & & & Quant & Valor & Quant & Valor & Quant & Valor \\
\hline \multicolumn{9}{|l|}{ 2. SERVIÇOS } \\
\hline Limpeza da área & $\mathrm{d} / \mathrm{H}$ & 25,00 & 10 & 250,00 & & & & \\
\hline Marcação de linhas & $\mathrm{d} / \mathrm{H}$ & 25,00 & 3 & 75,00 & & & & \\
\hline Marcação de covas & $\mathrm{d} / \mathrm{H}$ & 25,00 & 2 & 50,00 & & & & \\
\hline Coveamento & $\mathrm{d} / \mathrm{H}$ & 25,00 & 11 & 275,00 & & & & \\
\hline \multicolumn{9}{|l|}{ Transporte interno de } \\
\hline Insumos & $\mathrm{d} / \mathrm{H}$ & 25,00 & 1 & 25,00 & & & & \\
\hline Calagem e Adubação na cova & $d / H$ & 25,00 & 3 & 75,00 & & & & \\
\hline Plantio e replantio & $d / H$ & 25,00 & 8 & 200,00 & & & & \\
\hline Combate a formigas & $d / H$ & 35,00 & 2,5 & 87,50 & 2 & 70,00 & 2 & 70,00 \\
\hline $\begin{array}{l}\text { Capina manual de coroamento } \\
\text { ou na linha }\end{array}$ & $\mathrm{d} / \mathrm{H}$ & 25,00 & 9 & 225,00 & 6 & 150,00 & 6 & 150,00 \\
\hline Roçagem manual & $d / H$ & 25,00 & 7 & 175,00 & 6 & 150,00 & 6 & 150,00 \\
\hline $\begin{array}{l}\text { Construção/Manutenção } \\
\text { Aceiros }\end{array}$ & $\mathrm{d} / \mathrm{H}$ & 25,00 & 7 & 175,00 & 6 & 150,00 & 4 & 100,00 \\
\hline Corte e Toragem & $\mathrm{d} / \mathrm{H}$ & 25,00 & & 25,00 & & & & \\
\hline Baldeio & $\mathrm{d} / \mathrm{H}$ & 25,00 & & 25,00 & & & & \\
\hline Carregamento & $\mathrm{d} / \mathrm{H}$ & 25,00 & & 25,00 & & & & \\
\hline Carvoejamento & $\mathrm{mdc}$ & 19,00 & & 16,00 & & & & \\
\hline Madeira & $\mathrm{m}^{3}$ & 14,00 & & & & & & \\
\hline SUB TOTAL SERVIÇOS & $\mathbf{R} \$$ & & & 1612,50 & & 520,00 & & 470,00 \\
\hline TOTAL & $\mathbf{R} \mathbf{S}$ & & & 2508,35 & & 664,40 & & 512,40 \\
\hline
\end{tabular}

Fonte: Adaptado de CEDAGRO (2010) e EMATER (2008a). 
Tabela 1 - Continuação.

\begin{tabular}{|c|c|c|c|c|c|c|c|c|}
\hline \multirow{3}{*}{ ITENS DE CUSTO } & \multirow{3}{*}{ Unidade } & \multirow{3}{*}{$\begin{array}{c}\text { Valor } \\
\text { Unitário }\end{array}$} & \multicolumn{6}{|c|}{ Período } \\
\hline & & & \multicolumn{2}{|c|}{$4 .^{\circ}$ ao $6 .^{\circ}$ ano } & \multicolumn{2}{|c|}{ 7. Ano } & \multicolumn{2}{|c|}{$14 .^{\circ}$ ano } \\
\hline & & & Quant & Valor & Quant & Valor & Quant & Valor \\
\hline \multicolumn{9}{|l|}{ 1. INSUMOS } \\
\hline Mudas (Plantio e Replantio) & ud & 0,30 & & & & & & \\
\hline Irrigação & ud & 110,00 & & & & & & \\
\hline Calcário & $T$ & 85,00 & & & & & & \\
\hline \multicolumn{9}{|l|}{ Fertilizantes } \\
\hline Nitrogênio $-\mathrm{N}$ & $\mathrm{Kg}$ & 2,95 & & & & & & \\
\hline Fósforo - $\mathrm{P}_{2} \mathrm{O}_{5}$ & $\mathrm{Kg}$ & 2,67 & & & & & & \\
\hline Potássio - $\mathrm{K}_{2} \mathrm{O}$ & $\mathrm{Kg}$ & 3,50 & & & & & & \\
\hline Formicida & $\mathrm{Kg}$ & 10,60 & 3 & 31,80 & 1 & 10,60 & & \\
\hline Cupinicida & $\mathrm{Kg}$ & 102,00 & & & & & & \\
\hline SUB TOTAL INSUMOS & $\mathbf{R} \$$ & & & 31,80 & & 10,60 & & \\
\hline \multirow{3}{*}{ ITENS DE CUSTO } & \multirow{3}{*}{ Unidade } & \multirow{3}{*}{$\begin{array}{c}\text { Valor } \\
\text { Unitário }\end{array}$} & \multicolumn{6}{|c|}{ Período } \\
\hline & & & \multicolumn{2}{|c|}{$\begin{array}{l}4 .^{\circ} \text { ao } 6 .^{\circ} \text { ano e } \\
10 . .^{\circ} \text { ao } 13 .^{\circ} \text { ano }\end{array}$} & \multicolumn{2}{|c|}{ 7. Ano } & \multicolumn{2}{|c|}{$14 .^{\circ}$ ano } \\
\hline & & & Quant & Valor & Quant & Valor & Quant. & Valor \\
\hline \multicolumn{9}{|l|}{ 2. SERVIÇOS } \\
\hline Limpeza da área & $d / H$ & 25,00 & & & & & & \\
\hline Marcação de linhas & $d / H$ & 25,00 & & & & & & \\
\hline Marcação de covas & $\mathrm{d} / \mathrm{H}$ & 25,00 & & & & & & \\
\hline Coveamento & $\mathrm{d} / \mathrm{H}$ & 25,00 & & & & & & \\
\hline \multicolumn{9}{|l|}{ Transporte interno de } \\
\hline Insumos & $d / H$ & 25,00 & & & & & & \\
\hline $\begin{array}{l}\text { Calagem e Adubação na } \\
\text { cova }\end{array}$ & $d / H$ & 25,00 & & & & & & \\
\hline Plantio e replantio & $d / H$ & 25,00 & & & & & & \\
\hline Combate a formigas & $d / H$ & 35,00 & 5 & 175,00 & 2 & 70,00 & & \\
\hline $\begin{array}{l}\text { Capina manual de } \\
\text { coroamento ou na linha }\end{array}$ & $\mathrm{d} / \mathrm{H}$ & 25,00 & & & & & & \\
\hline Roçagem manual & $d / H$ & 25,00 & & & & & & \\
\hline $\begin{array}{l}\text { Construção/Manutenção } \\
\text { Aceiros }\end{array}$ & $d / H$ & 25,00 & 12 & 300,00 & & & & \\
\hline Corte e Toragem & $d / H$ & 25,00 & & & 20 & 500,00 & 18 & 450,00 \\
\hline Baldeio & $d / H$ & 25,00 & & & 24 & 600,00 & 23 & 575,00 \\
\hline Carregamento & $\mathrm{d} / \mathrm{H}$ & 25,00 & & & 29 & 725,00 & 27 & 675,00 \\
\hline Carvoejamento & $\mathrm{mdc}$ & 19,00 & & & 165 & 3135,00 & & \\
\hline Madeira & $\mathrm{m}^{3}$ & 14,00 & & & & & 110 & 1540,00 \\
\hline SUB TOTAL SERVIÇOS & $\mathbf{R} \mathbf{\$}$ & & & 475,00 & & 5030,00 & & 3240,00 \\
\hline TOTAL & $\mathbf{R} \$$ & & & 506,80 & & 5040,60 & & 3240,00 \\
\hline
\end{tabular}

Fonte: Adaptado de CEDAGRO (2010) e EMATER (2008a).

O custo de carbonização foi calculado com base em dados de empresas especializadas, sendo fixado em $\mathrm{R} \$ 40,00 /$ mdc (metro de carvão).

O valor de venda do carvão vegetal foi de $\mathrm{R} \$ 112,50 / \mathrm{mdc}$, preço de venda do carvão em Belo Horizonte (MG), em abril de 2010 (CIFLORESTAS, 2010a).

O valor de venda da madeira em tora para serraria serrada foi de $\mathrm{R} \$ 150,00 / \mathrm{m}^{3}$, preço de venda da madeira serrada na Zona da Mata (MG), em novembro de 2009 (Cl-FLORESTAS, 2010b).

\subsection{Custos e receitas das unidades demonstrativas}

Na unidade regional Viçosa, município de Viçosa, o custo total de implantação foi de $\mathrm{R} \$$ $1.212,00$ (Tabela 2). Os insumos foram responsáveis por $82,67 \%$ dos custos, justifica-se principalmente pelo custo com adubação (plantio e cobertura), $\mathrm{R} \$ 798,00$.

A produção total de milho no primeiro ano foi de $1.920 \mathrm{~kg} / \mathrm{ha}$, com o valor da produção sendo de $\mathrm{R} \$ 960,00$. Com isso, obteve-se um saldo negativo, de $\mathrm{R} \$ 252,00$. 
Tabela 2 - Relação de insumos e serviços utilizados (1ha) no município de Viçosa (MG).

\begin{tabular}{lcccc}
\hline Especificação & Unidade & Quantidade & Valor unitário & Total \\
\hline A - Insumos & & & & \\
\hline Semente de gramínea & $\mathrm{Kg}$ & 10 & 3,00 & 30,00 \\
Semente de milho & $\mathrm{Kg}$ & 20 & 3,00 & 60,00 \\
Adubo de plantio: NPK (08-28-16) & $\mathrm{SC}$ & 10 & 51,00 & 510,00 \\
Adubação de cobertura: NPK (30-00-10) & $\mathrm{SC}$ & 6 & 48,00 & 288,00 \\
Calcário & $\mathrm{T}$ & 2 & 27,00 & 54,00 \\
Herbicida (glifosato) & Litro & 5 & 12,00 & 60,00 \\
\hline B - Serviços & & & & \\
\hline Aplicação de herbicida & $\mathrm{d} / \mathrm{h}$ & 1 & 20,00 & 20,00 \\
Aplicação de calcário & $\mathrm{d} / \mathrm{h}$ & 1 & 20,00 & 20,00 \\
Plantio e adubação & $\mathrm{d} / \mathrm{h}$ & 2 & 20,00 & 40,00 \\
Adubação de cobertura & $\mathrm{d} / \mathrm{h}$ & 1 & 20,00 & 20,00 \\
Colheita & $\mathrm{d} / \mathrm{h}$ & 4 & 20,00 & 80,00 \\
Transporte & $\mathrm{d} / \mathrm{h}$ & 2 & 20,00 & 40,00 \\
\hline Total R\$ & & & & $1.212,00$ \\
\hline
\end{tabular}

Fonte: EMATER (2008a).

Na unidade regional Ponte Nova, município de São Pedro dos Ferros, o custo total de implantação foi de R $\$ 1.821,70$ (Tabela 3 ). Os insumos foram responsáveis por $68,16 \%$ dos custos.

Foram necessárias duas dessecações na área, o que aumentou o gasto com herbicidas e mãode-obra. A produtividade de milho foi de $4.200 \mathrm{~kg} / \mathrm{ha}$, ficando limitada pela estiagem prolongada, pela competição do milho com o capim colonião (banco de sementes e raízes). 0 valor da produção no primeiro ano foi de $R \$ 2.079,00$, sendo a receita líquida $R \$ 257,30$.

Tabela 3 - Relação de insumos e serviços utilizados (1ha) no município de São Pedro dos Ferros (MG).

\begin{tabular}{lcccc}
\hline Especificação & Unidade & Quantidade & $\begin{array}{l}\text { Valor } \\
\text { unitário }\end{array}$ & Total \\
\hline A - Insumos & & & & \\
\hline Semente de gramínea & $\mathrm{Kg}$ & 20 & 3,25 & 65,00 \\
Semente de milho & $\mathrm{Kg}$ & 20 & 2,60 & 52,00 \\
Adubação de plantio: NPK (08-28-16) & $\mathrm{SC}$ & 8 & 55,50 & 444,00 \\
Adubação de cobertura: NPK (30-00-10) & $\mathrm{SC}$ & 8 & 48,00 & 384,00 \\
Calcário & $\mathrm{T}$ & 0,6 & 120,00 & 72,00 \\
Herbicida (glifosato) & Litro & 10 & 15,00 & 150,00 \\
Herbicida (DMA) & Litro & 3 & 18,60 & 55,80 \\
Óleo diesel & Litro & 10 & 1,89 & 18,90 \\
Subtotal Insumos & & & & $1.241,70$ \\
\hline B - Serviços & & & & \\
\hline Aplicação de herbicida & $\mathrm{d} / \mathrm{h}$ & 5 & 15,00 & 75,00 \\
Aplicação de calcário & $\mathrm{d} / \mathrm{h}$ & 2 & 15,00 & 30,00 \\
Plantio + adubação & $\mathrm{d} / \mathrm{h}$ & 5 & 15,00 & 75,00 \\
Adubação de cobertura & $\mathrm{d} / \mathrm{h}$ & 4 & 15,00 & 60,00 \\
Colheita & $\mathrm{d} / \mathrm{h}$ & 15 & 17,00 & 255,00 \\
Transporte /debulha & $\mathrm{d} / \mathrm{h}$ & 5 & 17,00 & 85,00 \\
Subtotal serviços & & & & 580,00 \\
\hline Total R\$ & & & & $1.821,70$ \\
\hline
\end{tabular}

Fonte: EMATER (2008b). 
Na unidade regional Viçosa, município de Senador Firmino, o custo total de implantação foi de $\mathrm{R} \$ 1.739,60$ (Tabela 4). Os insumos foram responsáveis por 79,74\% dos custos. A produção total de milho no primeiro ano, foi de $2.998 \mathrm{~kg} / \mathrm{ha}$, o valor da produção foi de $\mathrm{R} \$ 999,00$ e apresentando saldo de $\mathrm{R} \$ 740,60$.

Tabela 4 - Relação de insumos e serviços utilizados (1ha) no município de Senador Firmino (MG).

\begin{tabular}{|c|c|c|c|c|}
\hline Especificação & Unidade & Quantidade & Valor unitário & Total \\
\hline \multicolumn{5}{|l|}{$A-$ Insumos } \\
\hline Semente de gramínea & $\mathrm{kg}$ & 25 & 5,60 & 140,00 \\
\hline Semente de milho & $\mathrm{kg}$ & 20,5 & 4,20 & 86,10 \\
\hline Adubação de plantio: NPK (8-28-16) +Zn+Bo & sc & 8 & 62,00 & 496,00 \\
\hline Superfosfato simples granulado & sc & 2 & 39,00 & 78,00 \\
\hline Formicida tipo "isca" & $\mathrm{kg}$ & 1,5 & 7,00 & 10,50 \\
\hline Agrosilicio & $\mathrm{T}$ & 2,5 & 70,00 & 175,00 \\
\hline Sulfato de amônio & sc & 6 & 38,00 & 228,00 \\
\hline Herbicida (glifosato) & litro & 3,5 & 17,00 & 59,50 \\
\hline Adubo NPK (6-30-6) & sc & 1 & 51,00 & 51,00 \\
\hline Mudas de eucalipto & milheiro & 0,5 & 75,00 & 37,50 \\
\hline Espalhante adesivo & litro & 0,05 & 10,00 & 0,50 \\
\hline Kit de calda viçosa & kit & 1 & 25,00 & 25,00 \\
\hline Subtotal Insumos & & & & $1.387,10$ \\
\hline \multicolumn{5}{|l|}{ B - Serviços } \\
\hline Reforma de cerca & $d / h$ & 2 & 15,00 & 30,00 \\
\hline Aplicação herbicida & $d / h$ & 0,5 & 15,00 & 7,50 \\
\hline Aplicação de agrosilício & $d / h$ & 2 & 15,00 & 30,00 \\
\hline Plantio e adubação & $\mathrm{d} / \mathrm{h} / \mathrm{a}$ & 4 & 30,00 & 120,00 \\
\hline Adubação cobertura & $\mathrm{d} / \mathrm{h}$ & 1 & 15,00 & 15,00 \\
\hline Combate à formiga & $d / h$ & 0,5 & 15,00 & 7,50 \\
\hline Pulverização calda viçosa & $d / h$ & 1 & 15,00 & 15,00 \\
\hline Colheita e transporte & $d / h$ & 5 & 15,00 & 75,00 \\
\hline Formação do eucalipto & $\mathrm{d} / \mathrm{ha}$ & 3,5 & 15,00 & 52,50 \\
\hline Subtotal serviços & & & & 352,50 \\
\hline Total R\$ & & & & $1.739,60$ \\
\hline
\end{tabular}

Fonte: EMATER (2008c).

\subsection{Critérios de avaliação econômica}

\subsubsection{Valor Presente Líquido - VPL}

A viabilidade econômica de um projeto analisada pelo VPL é indicada pela diferença positiva entre receitas e custos atualizados para uma determinada taxa de desconto (REZENDE; OLIVEIRA, 2001; SILVA et al., 2002). O critério de adoção deste método é o seguinte: um VPL positivo indica que o projeto é economicamente viável para uma determinada taxa utilizada. Deve-se aceitar o investimento com VPL positivo e, consequentemente, rejeitar aquele com VPL negativo.

$$
V P L=\sum_{j=1}^{n} \frac{R_{j}}{(1+i)^{j}}-\sum_{j=1}^{n} \frac{C_{j}}{(1+i)^{j}}
$$

Em que: $R j=$ receitas no período $\mathrm{j} ; C j=$ custos no período $j ; i=$ taxa de desconto; $j=$ período de 
ocorrência de $R j$ e $C j$; e $n=$ duração do projeto, em anos, ou em número de períodos de tempo.

\subsubsection{Valor Anual Equivalente - VAE}

O Valor Anual Equivalente (VAE) é a parcela periódica e constante necessária ao pagamento de uma quantia igual ao VPL da opção de investimento em análise ao longo de sua vida útil. O projeto será considerado economicamente viável quanto maior for o valor do benefício periódico equivalente (REZENDE; OLIVEIRA, 2001; SILVA et al., 2002).

$$
B P E=\frac{V P L \cdot i}{1-(1+i)^{n}}
$$

Em que: $V P L=$ valor presente líquido; e $n=$ duração do ciclo ou rotação em anos.

\subsubsection{Razão Benefício/Custo - B/C}

Este método consiste em determinar a relação entre o valor presente dos benefícios e o valor presente dos custos para uma determinada taxa de juros ou descontos. Um projeto é considerado viável economicamente se $B / C>1$. Entre dois ou mais projetos, o mais viável é aquele que apresentar o maior valor de $B / C$ (REZENDE e OLIVEIRA, 2001). Quando $B / C=1$, resulta em $V P L=0$; nesse caso, a TIR associada a um projeto pode também ser determinada como sendo a taxa que faz com que $\mathrm{B} / \mathrm{C}=1$.

$$
B / C=\frac{\sum_{j=0}^{n} R_{j}(1+i)^{-j}}{\sum_{j=0}^{n} C_{j}(1+i)^{-j}}
$$

Em que: $R j=$ receita no final do ano $j ; C i=$ custo no final do ano $j$; e $n=$ duração do projeto, em anos.

\subsubsection{Taxa Interna de Retorno - TIR}

A TIR é a taxa de desconto que iguala o valor atual das receitas futuras ao valor atual dos custos futuros do projeto, constituindo uma medida relativa que reflete o aumento no valor do investimento ao longo do tempo, com base nos recursos requeridos para produzir o fluxo de receitas (REZENDE; OLIVEIRA, 2001; SILVA et al., 2002).

$$
\sum_{j=1}^{n} \frac{R_{j}}{(1+T I R)^{j}}-\sum_{j=1}^{n} \frac{C_{j}}{(1+T I R)^{j}}=0
$$

Em que: $T I R=$ taxa interna de retorno; as demais variáveis já foram definidas.

\section{Resultados e Discussão}

\subsection{Simulação}

\subsubsection{Eucalipto em monocultivo}


O fluxo de caixa para o projeto está apresentado na Tabela 5, sendo construído anualmente, visando um horizonte de planejamento de 14 anos.

Tabela 5 - Fluxo de caixa para o projeto de reflorestamento com eucalipto visando à produção de carvão e madeira para serraria em Senador Firmino.

\begin{tabular}{cccccc}
\hline Ano & Receita & Custo & $\begin{array}{c}\text { Receita } \\
\text { descontada }\end{array}$ & Custo descontado & Saldo \\
\hline 1 & - & $2.500,00$ & - & 2298,85 & $-2.298,85$ \\
2 & - & 728,98 & - & 616,39 & $-616,39$ \\
3 & - & 538,01 & - & 418,31 & $-418,31$ \\
4 & - & 495,89 & - & 354,54 & $-354,54$ \\
5 & - & 495,89 & - & 326,02 & $-326,02$ \\
6 & - & 495,89 & - & 299,78 & $-299,78$ \\
7 & $22.050,00$ & $5.880,00$ & 12257,55 & 3268,68 & $8.988,87$ \\
8 & - & 666,86 & - & 340,88 & $-340,88$ \\
9 & - & 464,04 & - & 218,12 & $-218,12$ \\
10 & - & 495,89 & - & 214,33 & $-214,33$ \\
11 & - & 495,89 & - & 197,09 & $-197,09$ \\
12 & - & 495,89 & - & 181,23 & $-181,23$ \\
13 & - & 495,89 & - & 166,65 & $-166,65$ \\
14 & $44.100,00$ & $19.889,10$ & $13.627,90$ & 6146,18 & 7481,72 \\
\hline Total & $66.150,00$ & $34.138,22$ & $25.885,45$ & $15.047,07$ & $10.838,38$ \\
\hline
\end{tabular}

Fonte: Elaboração dos autores.

O Valor Presente Líquido (VPL) do projeto analisado foi maior do que zero, significando que é viável economicamente, sendo de $\mathrm{R} \$ 10.838,38$. Vale lembrar que o VPL representa o lucro do negócio corrigido pela taxa de juros (8,75\% a. a.), para um horizonte de 14 anos.

A Taxa Interna de Retorno (TIR) é a taxa que representa o retorno financeiro do projeto. A TIR apresentada foi de 19\%. A TIR obtida foi maior do que a taxa de desconto, que, no caso, é de $8,75 \%$ ao ano, o que significa que o projeto é viável, sob este ponto de vista.

O projeto é viável, uma vez que o Benefício Periódico Equivalente (BPE) se apresentou positivo, e que representa o lucro anual do negócio. De acordo com os resultados o lucro anual foi de $\mathrm{R} \$$ $1.372,49$.

A razão $B / C$ foi maior que 1 , indicando também que o projeto é viável economicamente. Essa razão foi de 1,72 , o que significa que as receitas superam os custos em $72 \%$.

\subsubsection{Unidade demonstrativa: Senador Firmino}

O sistema agrossilvipastoril implantado é composto por 75 árvores de eucalipto (considerando área igual a um hectare), juntamente com o milho nas entrelinhas. Realizou-se a colheita do milho durante dois anos. A Brachiaria foi plantada juntamente com o milho e após sua formação introduzse o novilho, no terceiro ano, com aproximadamente cinco arrobas. Após dois anos, vende-se o boi gordo. Portanto, a cada dois anos uma nova remessa de novilhos é colocada na área.

Considerou-se uma produção de 15 arrobas por hectare, sendo o preço de venda de $\mathrm{R} \$$ 71,00 a unidade.

O fluxo de caixa para o projeto está apresentado na Tabela 6 , sendo construído anualmente, visando um horizonte de planejamento de 14 anos. 
Tabela 6 - Fluxo de caixa para o sistema agroflorestal em Senador Firmino.

\begin{tabular}{cccccc}
\hline Ano & Receita & Custo & $\begin{array}{c}\text { Receita } \\
\text { descontada }\end{array}$ & $\begin{array}{c}\text { Custo } \\
\text { descontado }\end{array}$ & Saldo \\
\hline 1 & 999,00 & $1.739,60$ & 918,62 & 1599,63 & $-681,01$ \\
2 & 999,00 & 1511,1 & 844,71 & 1277,72 & $-433,01$ \\
3 & - & 936,56 & - & 728,20 & $-728,20$ \\
4 & - & 495,89 & - & 354,54 & $-354,54$ \\
5 & 1065,00 & 894,44 & 700,17 & 588,04 & 112,13 \\
6 & - & 495,89 & - & 299,78 & $-299,78$ \\
7 & $3.348,00$ & $5.880,00$ & 1861,15 & 3268,68 & $-1.407,53$ \\
8 & - & 666,86 & - & 340,88 & $-340,88$ \\
9 & 1065,00 & 862,59 & 500,59 & 405,45 & 95,14 \\
10 & - & 495,89 & - & 214,33 & $-214,33$ \\
11 & 1065,00 & 894,44 & 423,28 & 355,49 & 67,79 \\
12 & - & 495,89 & - & 181,23 & $-181,23$ \\
13 & - & 495,89 & - & 166,65 & $-166,65$ \\
14 & $6.696,00$ & $19.889,10$ & 2069,22 & 6146,18 & $-4.076,97$ \\
\hline Total & $15.237,00$ & $35.754,14$ & $7.317,74$ & $15.926,81$ & $-8.609,08$ \\
\hline
\end{tabular}

Fonte: Elaboração dos autores.

O Valor Presente Líquido (VPL) do projeto analisado foi negativo, sendo de $\mathrm{R} \$ 8.609,08$, indicando que esse sistema é inviável economicamente. Os demais critérios também indicam que o sistema é inviável. Neste caso, devia ser feito um melhor planejamento com relação à distribuição espacial do sistema agroflorestal, de modo que o mesmo pudesse auferir lucro.

Sendo assim, considerando-se que o eucalipto fosse plantado no espaçamento $14 \times 2 \mathrm{~m}$, obtendo-se 357 mudas por hectare, tem-se o fluxo de caixa estimado, conforme mostra a Tabela 7.

Tabela 7 - Fluxo de caixa para o sistema agroflorestal em Senador Firmino.

\begin{tabular}{cccccc}
\hline Ano & Receita & Custo & $\begin{array}{c}\text { Receita } \\
\text { descontada }\end{array}$ & $\begin{array}{c}\text { Custo } \\
\text { descontado }\end{array}$ & Saldo \\
\hline 1 & 999 & $1.739,60$ & 918,62 & 1599,63 & $-681,01$ \\
2 & 999 & 1511,1 & 844,71 & 1277,72 & $-433,01$ \\
3 & - & 936,56 & - & 728,2 & $-728,2$ \\
4 & - & 495,89 & - & 354,54 & $-354,54$ \\
5 & 1065 & 894,44 & 700,17 & 588,04 & 112,13 \\
6 & - & 495,89 & - & 299,78 & $-299,78$ \\
7 & $16.065,00$ & $5.880,00$ & 8930,5 & 3268,68 & $5.661,82$ \\
8 & - & 666,86 & - & 340,88 & $-340,88$ \\
9 & 1065 & 862,59 & 500,59 & 405,45 & 95,14 \\
10 & - & 495,89 & - & 214,33 & $-214,33$ \\
11 & 1065 & 894,44 & 423,28 & 355,49 & 67,79 \\
12 & - & 495,89 & - & 181,23 & $-181,23$ \\
13 & - & 495,89 & - & 166,65 & $-166,65$ \\
14 & $32.130,00$ & $19.889,10$ & 9928,9 & 6146,18 & $3.782,72$ \\
\hline Total & $53.388,00$ & $35.754,14$ & $22.246,77$ & $15.926,81$ & $6.319,96$ \\
\hline
\end{tabular}

Fonte: Elaboração dos autores.

O Valor Presente Líquido (VPL) do sistema agroflorestal simulado foi de R\$ 6.319,96/ha, significando que é viável economicamente. Os demais critérios de análise financeira também indicaram viabilidade, a TIR foi de $23 \%$, o BPE foi de $\mathrm{R} \$ 800,31$ e a razão B/C igual a 1,39.

Considerando que o plantio do eucalipto fosse realizado no espaçamento $10 \times 6 \mathrm{~m}$, ou seja, 166 árvores por hectare, o sistema agroflorestal apresentaria o fluxo de caixa como mostrado na Tabela 8. 
Tabela 8 - Fluxo de caixa para o sistema agroflorestal com o eucalipto no espaçamento 10 x $6 \mathrm{~m}$.

\begin{tabular}{cccccc}
\hline Ano & Receita & Custo & $\begin{array}{c}\text { Receita } \\
\text { descontada }\end{array}$ & $\begin{array}{c}\text { Custo } \\
\text { descontado }\end{array}$ & Saldo \\
\hline 1 & 999 & $1.739,60$ & 918,62 & 1599,63 & $-681,01$ \\
2 & 999 & 1511,1 & 844,71 & 1277,72 & $-433,01$ \\
3 & 0 & 936,56 & 0 & 728,2 & $-728,2$ \\
4 & 0 & 495,89 & 0 & 354,54 & $-354,54$ \\
5 & 1065 & 894,44 & 700,17 & 588,04 & 112,13 \\
6 & 0 & 495,89 & 0 & 299,78 & $-299,78$ \\
7 & $7.425,00$ & $5.880,00$ & 4127,54 & 3268,68 & 858,86 \\
8 & 0 & 666,86 & 0 & 340,88 & $-340,88$ \\
9 & 1065 & 862,59 & 500,59 & 405,45 & 95,14 \\
10 & 0 & 495,89 & 0 & 214,33 & $-214,33$ \\
11 & 1065 & 894,44 & 423,28 & 355,49 & 67,79 \\
12 & 0 & 495,89 & 0 & 181,23 & $-181,23$ \\
13 & 0 & 495,89 & 0 & 166,65 & $-166,65$ \\
14 & $14.850,00$ & $19.889,10$ & 4588,99 & 6146,18 & - \\
\hline Total & $27.468,00$ & $35.754,14$ & $12.103,90$ & $15.926,81$ & $3.822,91$ \\
\hline
\end{tabular}

Fonte: Elaboração dos autores.

Observa-se que o sistema não é viável economicamente, pois o VPL é negativo, sendo assim o número de árvores no sistema agroflorestal influencia significativamente o retorno financeiro do investimento.

\section{Conclusões}

O sistema agroflorestal implantado no município de Senador Firmino é inviável economicamente, de acordo com os critérios de avaliação econômica utilizados na análise.

O componente agrícola do sistema agroflorestal analisado, demonstrou ser importante no sentido de amortização dos custos, além de fornecer renda extra ao pequeno produtor rural.

Os sistemas agroflorestais analisados apresentam diferentes estruturas de custos, os quais variam de região para região e conforme o espaçamento estudado. Portanto tanto os custos quanto os preços de vendas dos produtos poderão modificar os cenários de lucro para prejuízo, ou vice-versa.

\section{Agradecimentos}

À CAPES pelo apoio financeiro; à EMATER, pela disponibilização dos dados e à Universidade Federal de Viçosa, pela infraestrutura.

\section{Cost and income analysis of agroforestry system in Zona da Mata (MG)}

\section{Abstract}

This research was carried out with the objective of surveying the production costs of agroforestry systems established in the Zona da Mata (MG) - Brazil (Forest Zone) and to simulate scenarios to improve these systems. Data from the projects carried out in the Unidades de Experimentação Integração Lavoura Pecuária e Floresta, in the years 2007/2008 were used, supplied by the Empresa de Assistência Técnica e Extensão Rural de Minas Gerais (EMATER (MG) - Enterprise of Technical Assistance and Rural Extension of Minas Gerais), and by the Universidade Federal de Viçosa. The production costs of an agroforestry system were compared to the eucalypt monoculture, as well as 
to the variations in income due to the planting spacing variation. The eucalyptus in monoculture had better results, being the best income project. As the spacing is increased between the eucalyptus trees, there is an increase of area available for corn planting and cattle raising. But as proved by the results, this gain in area does not offer the same financial return if planted with trees.

Keywords: Agroforestry system. Forest planning. Forest economics.

\section{Referências Bibliográficas}

CENTRO DE DESENVOLVIMENTO DO AGRONEGÓCIO - CEDAGRO. Coeficientes técnicos e custos de produção na agricultura do Espírito Santo - Eucalipto. Disponível em: <http://www.cedagro.org.br/>. Acesso em: 11 maio 2010.

CENTRO DE INTELIGÊNCIA EM FLORESTAS - CIFLORESTAS. Preço de venda do carvão em Belo Horizonte (MG). Disponível em: <http://www.ciflorestas.com.br/>. Acesso em: 26 abr. 2010a.

CENTRO DE INTELIGÊNCIA EM FLORESTAS - CIFLORESTAS. Preço de venda da madeira serrada na Zona da Mata (MG). Disponível em: <http://www.ciflorestas.com.br/>. Acesso em: 26/04/2010b.

CORDEIRO, S. A.; SILVA, M. L.; JACOVINE, L. A. G.; VALVERDE, S. R.; SOARES, N. S. Contribuição do fomento do órgão florestal de Minas Gerais, na lucratividade e na redução de riscos para o produtor rural. Revista Árvore, Viçosa, 2010, v. 34, n. 2, p. 367-376, 2010.

DANIEL, O.; BITTENCOURT D.; GELAIN, E. Avaliação de um sistema agroflorestal eucalipto-milho no Mato Grosso do Sul. Agrossilvicultura, Viçosa, 2004, v. 1, n. 1, p. 15-28, 2004.

DUBE, F. Estudos técnicos e econômicos de sistemas agroflorestais com Eucalyptus sp. no noroeste do Estado de Minas Gerais: 0 caso da Companhia Mineira de Metais. 1999. 146 f. Dissertação (Mestrado em Ciência Florestal) Universidade Federal de Viçosa, Viçosa, 1999.

EMATER, UFV. Relatório final - Unidades de Experimentação Integração Lavoura Pecuária e Floresta 2007/2008. Unidade Regional - Viçosa. 2008a. 4 p.

Relatório final - Unidades de Experimentação Integração Lavoura Pecuária e Floresta 2007/2008. Unidade Regional - Ponte Nova. 4pg. 2008b.

. Unidade Regional - Viçosa, município Senador Firmino. 2008c. 4 p.

LOPES W. P. de; PAULA, A. de; SEVILHA, A. C.; SILVA, A. F. da. Composição da flora arbórea de um trecho de floresta estacional no Jardim Botânico da Universidade Federal de Viçosa (face sudoeste), Viçosa, Minas Gerais. Revista Árvore, v. 26, n. 3, p. 339-347, 2002.

MARQUES, L. C. T. Comportamento inicial de paricá, tatajuba e eucalipto, em plantio consorciado com milho e capim-marandu, em Paragominas, Pará. 1990. 92p. Dissertação (Mestrado em Ciência Florestal) - Universidade Federal de Viçosa. Viçosa, 1990.

REZENDE, J. L. P. de; OLIVEIRA, A. D. de. Análise econômica e social de projetos florestais. Viçosa: UFV, 2001, 389 p.

SILVA, M. L. da; JACOVINE, L. A. G.; VALVERDE, S. L. Economia florestal. Viçosa: UFV, 2002. 178 p.

SOUZA, A. N. de; OLIVEIRA, A. D. de; SCOLFORO J. R. S.; REZENDE, J. L. P. de; MELLO, J. M. de. Viabilidade econômica de um sistema agroflorestal. Revista Cerne, v. 13, n.1, p. 96-106, 2007.

VALE, R. S. do. Agrossilvicultura com eucalipto como alternativa para o desenvolvimento sustentável da Zona da Mata de minas Gerais. 2004. 112 f. Tese (Doutorado em Ciência Florestal) - Universidade Federal de Viçosa. Viçosa, 2004.

Histórico

Recebido em: 27/07/2013

Aceito em: 04/02/2014 